\title{
Achieving 6.7\% Efficiency In P3HT / Indene-C70 Bisadduct Solar Cells Through The Control Of Vertical Volume Fraction Distribution And Optimized Regio-Isomer Ratios
}

Dimitar I. Kutsarov, Ilija Rašović, Alexandros Zachariadis, Argiris Laskarakis, Maria A. Lebedeva, Kyriakos Porfyrakis, Christopher A. Mills, Michail J. Beliatis, Brett Fisher, Kirsten Bruchlos, Sabine Ludwigs, Stergios Logothetidis, S. Ravi P. Silva*

D. I. Kutsarov, Dr. C. A. Mills, Dr. M. J. Beliatis, B. Fisher, Prof. S. R. P. Silva Advanced Technology Institute, University of Surrey, Guildford, Surrey, GU2 7XH, UK. E-mail: s.silva@surrey.ac.uk

I. Rašović, Dr. M. A. Lebedeva, Dr. K. Porfyrakis

Department of Materials, University of Oxford, Parks Road, Oxford, OX1 3PH, UK

A. Zachariadis, Dr. A. Laskarakis, Prof. S. Logothetidis Aristotle University of Thessaloniki, Physics Department, Laboratory for Thin Films, GR54124 Thessaloniki, Greece

K. Bruchlos, Prof. S. Ludwigs

IPOC-Functional Polymers, University of Stuttgart, 70569 Stuttgart, Germany

Dr. C. A. Mills

Advanced Coatings Group, Tata Steel Research Development and Technology, Voyager building, 9 Sir William Lyon Road, Coventry, CV4 7EZ, UK

Keywords: polymer solar cells; high-efficiency; vertical phase separation; regio-isomerism; P3HT-ICBA 
Indene $\mathrm{C}_{60}$ and $\mathrm{C}_{70}$ bisadducts ( $\mathrm{IC}_{60} \mathrm{BA}$ and $\mathrm{IC}_{70} \mathrm{BA}$ ) have relatively high lowest unoccupied molecular orbital (LUMO) energies. In P3HT-based polymer solar cells (PSCs), this produces an increase in open-circuit voltage $\left(\mathrm{V}_{\mathrm{OC}}\right)$ and power conversion efficiency (PCE). However, ICBA synthesis produces a mixture of regio-isomers with different indene spatial orientations $\left(2,5\right.$, and 12 o'clock) that alter the $\mathrm{IC}_{70} \mathrm{BA}$ molecular packing when mixed with P3HT. In this paper, we examine how the $\mathrm{IC}_{70} \mathrm{BA}$ regio-isomerism affects the $\mathrm{PSC}$ performance by investigating the molecular packing of $\mathrm{P} 3 \mathrm{HT}: \mathrm{IC}_{70} \mathrm{BA}$ layers with different regio-isomeric ratios. For the first time, we use non-destructive spectroscopic ellipsometry to investigate the effect of the fabrication conditions on the $\mathrm{P} 3 \mathrm{HT} / \mathrm{IC}_{70} \mathrm{BA}$ vertical volume fraction distribution and attribute our results to the spatial arrangement of the regio-isomers. We demonstrate that this unambiguously affects the PSC performance. As a result, we repeatedly attain record device efficiencies for standard architecture P3HT:IC 70 BA PSCs with photoactive areas of $0.43 \mathrm{~cm}^{2}$, achieving $5.9( \pm 0.4) \%$ PCE $(\mathrm{n}=15)$. With control of the $\mathrm{IC}_{70} \mathrm{BA}$ constituent, device PCEs vary from below $2.2 \%$ to peak values above $6.7 \%$, amongst the highest recorded PCEs for a P3HT combination, highlighting the importance of the molecular phase separation for high efficiency devices. 


\section{Introduction}

Over the last two decades, progress in understanding the science of polymer solar cells (PSCs) has allowed for power conversion efficiencies (PCE) of less than 1\% in 1995 to advance above 10\%. ${ }^{[1-4]}$ These high PCEs, combined with low cost, light weight, flexibility, semitransparency, and high throughput fabrication, point to a promising future for PSCs, and mean that they can be complementary to their inorganic counterparts. In order to deliver suitable power for energizing in- and outdoor applications, an appropriate understanding of the factors influencing the donor-acceptor (D-A) bulk-heterojunction (BHJ) formation kinetics is required, suitable for achieving high PCE and technological up-scaling. However, PCEs are commonly reported for single "hero" devices with areas rarely exceeding $0.1 \mathrm{~cm}^{2}$, which puts their applicability for use in technology into perspective. ${ }^{[5]}$ Only a few groups report larger active areas, or present results on a module scale. ${ }^{[6-9]}$

Using a D-A blend with a more ordered spatial molecular packing would benefit the exciton dissociation and improve the charge carrier mobilities and transport characteristics, due to reduced hopping distances along closely packed D-A nanodomains, allowing thicker BHJs for greater light absorption. ${ }^{[10]}$ Poly(3-hexylthiophene) (P3HT, Figure 1a) is among the most well-known of conjugated polymers, which in combination with [6,6]-Phenyl $\mathrm{C}_{61}$ butyric acid methyl ester $\left(\mathrm{PC}_{60} \mathrm{BM}\right.$, Figure 1b), represent one of the most widely studied PSC D-A blends. ${ }^{[11]}$ The major advantages of P3HT are its low cost and strong peak extinction coefficient $\left(10^{5} \mathrm{~cm}^{-1}\right) \cdot{ }^{[12]}$ Its tendency to form self-organized crystalline structures improves the charge transport and reduces recombination losses within the $\mathrm{BHJ}$, essential to accomplish reproducible up-scaled devices with high PCE. Several groups have already demonstrated the fabrication of large area PSCs, or modules, utilizing P3HT as an electron-donating material. ${ }^{[7}$, ${ }^{13,14]}$ Achieving a balanced D-A material distribution, and hence a favorable BHJ morphology and phase separation, is essential for improving device characteristics such as short circuit current density $\left(\mathrm{J}_{\mathrm{SC}}\right)$, fill factor $(\mathrm{FF})$, and PCE. ${ }^{[15,16]}$ To accomplish this, the deposited 
photoactive layer can be subject to solvent annealing (SA) and/or thermal annealing (TA). ${ }^{[17-}$ ${ }^{19]}$ The vertical D-A material distribution is furthermore dependent on the diffusion dynamics of the materials according to their surface energies. Hence, understanding this behavior using a non-destructive optical characterization technique is essential to allow the knowledge to be transferable to similar D-A systems.

a)

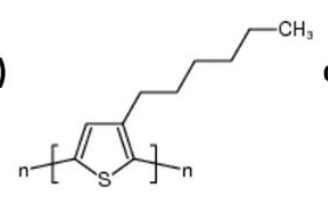

b)

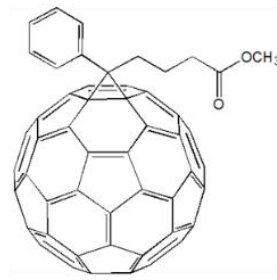

c)

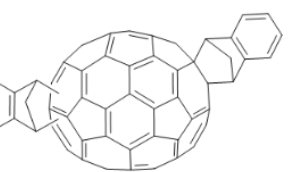

d)

e)
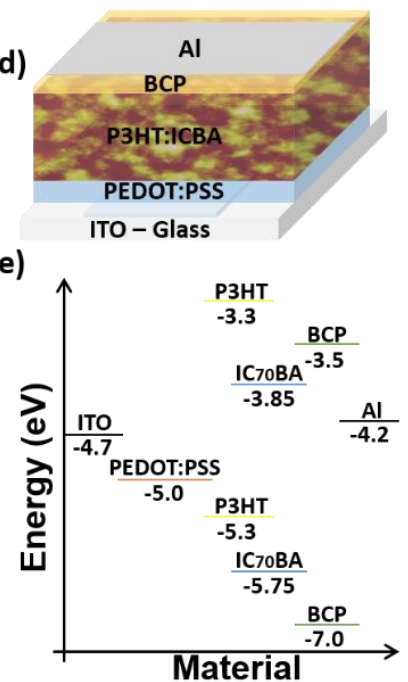

Figure 1. Chemical structures of (a) P3HT, (b) $\mathrm{PC}_{60} \mathrm{BM}$, and (c) $\mathrm{IC}_{70} \mathrm{BA}$. (d) Structure of the PSC devices fabricated for this study. e) Their energy diagram (The HOMO level of $\mathrm{IC}_{70} \mathrm{BA}$ was calculated according to the band gap reported by He et al. $\left.{ }^{[24]}\right)$.

The maximum obtainable open circuit voltage $\left(V_{\text {OC }}\right)$ for an organic D-A system is considered to be equal to the energy difference between the highest occupied molecular orbital (HOMO) level of the donor and the lowest unoccupied molecular orbital (LUMO) level of the acceptor, which in the case of $\mathrm{P} 3 \mathrm{HT}: \mathrm{PC}_{60} \mathrm{BM}$ is approx. $0.6 \mathrm{~V} \cdot{ }^{[20]}$ As a consequence, average device PCEs are around 3\%. ${ }^{[21]}$ However, theoretical PCEs above $8 \%$ have been hypothesized for P3HT-based PSCs. ${ }^{[22]}$ This prediction was acknowledged, and various new fullerene derivatives with higher LUMO levels compared to PCBM, have been synthesized. ${ }^{[23]}$ Prominent examples are the indene bis-functionalized $\mathrm{C}_{60}$ and $\mathrm{C}_{70}$ molecules, $\mathrm{IC}_{60} \mathrm{BA}$ and $\mathrm{IC}_{70} \mathrm{BA}$ (Figure 1c). The approximately $0.2 \mathrm{eV}$ higher LUMO energies of $\mathrm{IC}_{60} \mathrm{BA}$ and $\mathrm{IC}_{70} \mathrm{BA}$ enhance the $\mathrm{V}_{\mathrm{OC}}$ and PCEs of $5.44 \%$ and $5.64 \%$ have been reported for small device areas of approx. 0.1 and $0.04 \mathrm{~cm}^{2}$ respectively. ${ }^{[24,25]}$ 
Subsequently, work has been undertaken to understand the P3HT:ICBA blend characteristics and achieve the predicted $8 \%$ PCE. ${ }^{[26-30]}$ However, the majority of the reported PCEs are measured for devices with active areas smaller than $0.1 \mathrm{~cm}^{2}$ and are a product of tailoring the device fabrication conditions. It is arguable whether high PCE values are feasible for upscaled device areas where the high series resistance of the transparent electrode, i.e. indium tin oxide (ITO), has to be considered, although it may be possible in the future to replace the ITO for large area electronics applications. ${ }^{[31-34]}$

Currently, there is no full understanding of the P3HT:ICBA BHJ formation kinetics as a function of the fabrication conditions and the intrinsic properties of the materials, knowledge vital for fabricating high performance large-area PSCs. There are only a handful of publications that take into consideration the regio-isomeric properties of the $\mathrm{IC}_{70} \mathrm{BA}$ molecule and relate it to the $\mathrm{PCE} .{ }^{[35-37]}$ Isolated single $\mathrm{IC}_{70} \mathrm{BA}$ isomers have been shown to alter the device PCE ${ }^{[38]}$ However, there is little information on how a mixture of regio-isomers affects the device output. To address this point, we produced a number of standard architecture PSCs (Figure 1d and 1e) using processing conditions tailored for a $\mathrm{IC}_{70} \mathrm{BA}$ sample with a fixed regio-isomeric distribution (hereafter $\mathrm{IC}_{70} \mathrm{BA \# 1}$ ), and then transferred this knowledge to another $\mathrm{IC}_{70} \mathrm{BA}$ sample (hereafter $\mathrm{IC}_{70} \mathrm{BA \# 2}$ ) exhibiting a dissimilar regio-isomeric distribution, in order to investigate the importance of the regio-isomerism on the vertical phase separation of the P3HT:IC $70 \mathrm{BA}$ BHJ.

Informed by the current state-of-the-art for P3HT:ICBA PSCs, we conducted a thorough characterization of commercially sourced $\mathrm{P} 3 \mathrm{HT}$ and $\mathrm{IC}_{70} \mathrm{BA}$ to hypothesize the best conditions for achieving high PSC power outputs. We show a way to harness the excellent and well understood properties of $\mathrm{P} 3 \mathrm{HT}$ when used with $\mathrm{IC}_{70} \mathrm{BA}$. Unambiguous evidence to achieve high PCEs with P3HT-based PSCs is shown to be possible, but strongly dependent on the ratio distribution of the $\mathrm{IC}_{70} \mathrm{BA}$ regio-isomers. We set out a detailed characterization and understanding of the P3HT: $\mathrm{IC}_{70} \mathrm{BA}$ PSCs and convey a route towards the fabrication of large- 
area energy harvesting devices, with a view to providing usage in novel practical technologies. ${ }^{[39-41]}$

\section{Results and discussion}

Unlike the highly symmetric, football-shaped $\mathrm{C}_{60}, \mathrm{C}_{70}$ is an elongated spheroid, like a rugby ball. The Schlegel diagram of $\mathrm{C}_{70}$ (Figure 2a) shows that the polar $\alpha$ bonds are more strained than the bonds nearer the equator due to the higher radius of the curvature at the poles. Following a simple classification for describing bisadducts of $\mathrm{C}_{70}$ in a Newman-type projection (Figure 2b), there are two polar pentagons, each with five radiating $\alpha$ double bonds, ${ }^{[42]}$ which possess the highest reactivity due to the preferential strain energy relief. The two indene addends predominantly link to the fullerene cage across these bonds at the opposite poles, and can adopt a 2, 5, or 12 o'clock geometric relationship as shown in Figure 2c-2e. The current synthetic routes to fullerene bisadducts inevitably generate a mixture of regio-isomers, with only a few reports of producing isomerically pure compounds. ${ }^{[43-46]}$ This structural isomerism leads to structural and energetic disorder (different fullerene isomers exhibit dissimilar electronic energy levels and molecular packing), which can alter the electron mobility and charge carrier transport efficacy in the photoactive region and consequently the PSC device characteristics. ${ }^{[47,48]}$ Isolating particular single isomers has already proven to be an efficient, albeit time-consuming, route to improve various device characteristics. ${ }^{[36,37]}$ 


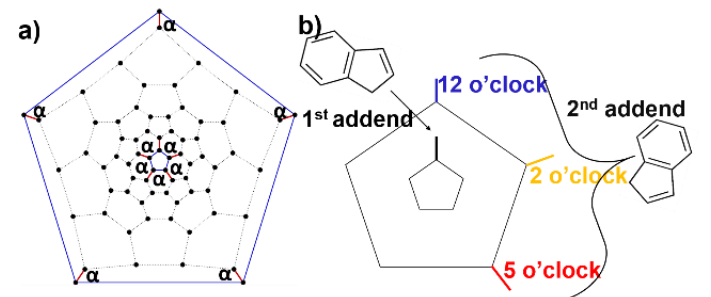

c)

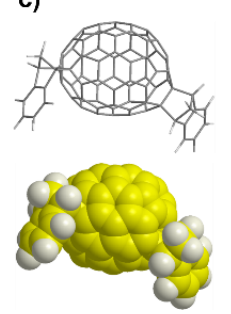

d)

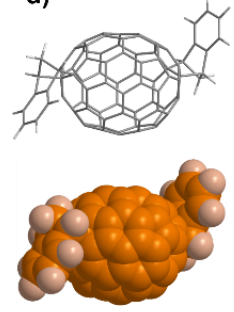

e)

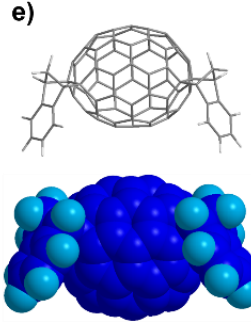

Figure 2. (a) $\mathrm{C}_{70}$ Schlegel diagram with the most reactive $\alpha$ bonds highlighted in red. (b) Simplified Newman-type projection of $\mathrm{C}_{70}$ showing its two reactive polar pentagons with attachment of first and second indene addends resulting in the formation of 2, 5, or 12 o'clock regioisomers of $\mathrm{IC}_{70} \mathrm{BA}$, as shown in (c), (d) and (e), respectively.

\subsection{Materials characterization}

Two different commercial $\mathrm{IC}_{70} \mathrm{BA}$ samples, were characterized using high performance liquid chromatography (HPLC) (see Supporting Section 1 and 2) revealing 99\% purity. The remaining $1 \%$ of the sample represents impurities such as indene- $\mathrm{C}_{70}$ monoadduct $\left(\mathrm{IC}_{70} \mathrm{MA}\right)$, indene- $\mathrm{C}_{70}$ tris-adduct ( $\mathrm{IC}_{70} \mathrm{TA}$ ) and pristine $\mathrm{C}_{70}$. Interestingly, the integration of the main HPLC peaks (A, B, and C in Figure S1 and S2 and Table S1 and S2) in $\mathrm{IC}_{70} \mathrm{BA}$ batch \#1 and \#2 show a different distribution of the regio-isomers (22\%, $43 \%$, and $35 \%$ vs. $16 \%, 36 \%$, and $48 \%$ ). This result implies that the synthesis and/or purification of the $\mathrm{IC}_{70} \mathrm{BA}$ can lead to different isomeric content in the sample, which can affect the spatial molecular packing of the D-A BHJ and alter the PSCs characteristics.

In order to ascribe each HPLC fraction to the corresponding $\mathrm{IC}_{70} \mathrm{BA}$ regio-isomer, UV-visible absorption (UV-vis) and proton nuclear magnetic resonance ( ${ }^{1} \mathrm{H}$ NMR) spectroscopy was employed. ${ }^{1} \mathrm{H}$ NMR of fraction C (Figure S4) shows two singlets and two doublets corresponding to the 8 aliphatic protons in the two indene addends indicating that the two indene groups are chemically and magnetically identical. This implies the highest symmetry 
group in the molecule $\left(\mathrm{c}_{2 \mathrm{v}}\right)$ most likely corresponds to a $12 \mathrm{o}$ 'clock isomer. This is consistent with the ${ }^{1} \mathrm{H}$ NMR spectrum reported previously. ${ }^{[36]}$ The UV-vis spectrum of fraction C (Figure S5) is also identical to that reported for the 12 o'clock isomer. ${ }^{[36]}$ Both fractions A and B show similar sets of signals with higher multiplicity corresponding to the two non-identical indene groups in each case. This is consistent with the lower symmetry expected for the 2 and 5 o'clock isomers. Furthermore, the UV-vis spectrum of fraction B is identical to that reported previously for the 2 o'clock isomer, and therefore fractions A and B can be tentatively assigned as 5 o'clock and 2 o'clock isomers, respectively. ${ }^{[36]}$

The corresponding fragments of the heteronuclear multiple-bond correlation spectroscopy (HMBC) NMR spectra of fractions A-C indicating the ${ }^{3} \mathrm{~J}\left(\mathrm{Ha}, \mathrm{C}_{\text {fullerene,eq }}\right)$ and ${ }^{3} \mathrm{~J}(\mathrm{Hb}$, $\mathrm{C}_{\text {fullerene,pole }}$ ) couplings for each of the fractions are shown in Figure S6. Careful analysis of the geometry of each of the $\mathrm{IC}_{70} \mathrm{BA}$ isomers (see Supporting Section 2) shows the shortest distance between the "pole" carbon atom and the indene addend at the opposite pole in the 2 o'clock isomer (8.36 $\AA$ ), followed by the 12 o'clock isomer (8.42 $\AA$ ), and 5 o'clock isomer (8.48 $\AA$ ). This allows us to unambiguously assign the isomers in fractions A, B, and C as described above and shown in the insets in Figure S6.

Cyclic voltammetry has been performed to determine the frontier orbital energy levels and the effective band gap. Based on the oxidative and reductive scans of P3HT films (Figure S7), and according to Supporting Equation 1 and 2, the HOMO and LUMO were calculated to be $-5.2 \mathrm{eV}$ and $-2.8 \mathrm{eV}$. The $\mathrm{IC}_{70} \mathrm{BA \# 1} \mathrm{LUMO}$ was calculated to be $-3.7 \mathrm{eV}$ (Figure S8); blends of P3HT:IC 70 BA\#1 show similar results (Figure S9).

\subsection{Thermal stability and phase transition of $I_{70} B A$}

Looking into the thermal stability of $\mathrm{IC}_{70} \mathrm{BA \# 1}$ in Figure $\mathrm{S} 10$, pristine $\mathrm{IC}_{70} \mathrm{BA \# 1}$ undergoes a gradual mass loss of $7 \%$ between $87{ }^{\circ} \mathrm{C}$ and $230{ }^{\circ} \mathrm{C}$. This gradual weight loss is most likely related to the evolution of volatile solvent residuals from the synthesis, but may also be due to partial decomposition or re-arrangement of impurities in the $\mathrm{IC}_{70} \mathrm{BA \# 1}$, or due to the breaking 
of indene- $\mathrm{C}_{70} \mathrm{C}-\mathrm{C}$ bonds. ${ }^{[36]}$ The $\mathrm{IC}_{70} \mathrm{BA \# 1}$ thermal stability was drastically improved when it was heated to $200{ }^{\circ} \mathrm{C}$ before undertaken thermogravimetric (TGA) analysis. No gradual mass loss was observed, implying that physical changes occur in the pristine $\mathrm{IC}_{70} \mathrm{BA \# 1}$ during annealing, separate from the indene loss which is predominant between $200-300{ }^{\circ} \mathrm{C}$, a result which implies that pristine $\mathrm{IC}_{70} \mathrm{BA \#} 1$ has a low temperature stability. The final $\mathrm{IC}_{70} \mathrm{BA \# 1}$ weight loss above $600{ }^{\circ} \mathrm{C}$ is due to the decomposition of the fullerene moiety. In a blend with P3HT, we noticed that $\mathrm{IC}_{70} \mathrm{BA \# 1}$ has a higher thermal stability (weight loss after the first decomposition is $17.2 \%$ lower in the blend). We propose that the improved thermal stability for the P3HT:IC $70 \mathrm{BA \# 1}$ blend arises from a more compact molecular packing, where segregated $\mathrm{IC}_{70} \mathrm{BA \# 1}$ regio-isomers are captured by the self-organized P3HT network. ${ }^{[49]}$ This assumption is supported by the phase transition behaviour of $\mathrm{IC}_{70} \mathrm{BA \# 1}$ in the differential scanning calorimetry (DSC) data in Figure S10b. The initial main endothermic peak between $90-135{ }^{\circ} \mathrm{C}$ (centred at $101.6{ }^{\circ} \mathrm{C}$ ) is related to a slow melting transition in the regio-isomeric $\mathrm{IC}_{70} \mathrm{BA \# 1}$ lattice, which could lead to a re-arrangement of the $\mathrm{IC}_{70} \mathrm{BA \# 1}$ molecules or semicrystallization of the material. The tail peak is likely to be associated with the subsequent release of solvents residing in voids. ${ }^{[36]}$ The absence of the peaks in the second heat-cool cycle suggests that these processes are complete after heating above $200{ }^{\circ} \mathrm{C}$ and are irreversible.

\subsection{P3HT:IC $70 B A$ optical properties}

Figure 3a shows the effect of annealing on the P3HT:IC ${ }_{70} B A \# 1$ absorption spectra. Clearly, films which were quickly dried after fabrication exhibit the lowest absorption. After SA the absorption spectra is red shifted, with a peak at $490 \mathrm{~nm}$ and two shoulders at approximately $552 \mathrm{~nm}$ and $598 \mathrm{~nm}$, which are related to an improved P3HT crystallinity. ${ }^{[50]}$ A TA step broadens the absorption spectra, with a further red shift of the main absorption peak. The highest crystallinity is observed for samples subjected to SA and subsequently TA, noticeable by the distinct vibronic shoulders at $548 \mathrm{~nm}$ and $601 \mathrm{~nm}$, and the shift of the main peak to 510 
nm. These vibronic shoulders are related to the inter- and intra-chain states of the P3HT film, with a high degree of self-organization and interchain interactions. This results in increased delocalization of the conjugated $\pi$ electrons and an increased $\pi-\pi^{*}$ optical transition, as evidenced by the red shift of the peak absorption. ${ }^{[50]}$ Increasing the TA temperature (Figure S11) reveals that all P3HT: $\mathrm{IC}_{70} \mathrm{BA \# 1}$ layers show similar optical characteristics, with a lower absorption for layers thermally annealed at $150{ }^{\circ} \mathrm{C}$ and $170{ }^{\circ} \mathrm{C}$. We ascribe this to aggregation within the regio-isomeric mixture and suggest that the interplane stacking of the $\mathrm{P} 3 \mathrm{HT}$ molecules is disturbed by the $\mathrm{IC}_{70} \mathrm{BA \# 1}$ clusters which impact the BHJ morphology. ${ }^{[27]}$ Similarly, examining the absorption spectra with respect to the spin-coating speed (Figure 3b) reveals the highest absorption for films deposited at the lowest spin-coating speeds, which is directly related to the film thickness (Figure S12). The absorption profile gradually decreases with the increased rotation velocity, until $750 \mathrm{rpm}$ where a step decrease in absorbance is observed. This finding corresponds somewhat to the data shown for films fabricated without the SA step (Figure 3a), suggesting that semi-dry P3HT:IC 70 BA\#1 layers are produced which are unresponsive to the subsequent SA step.

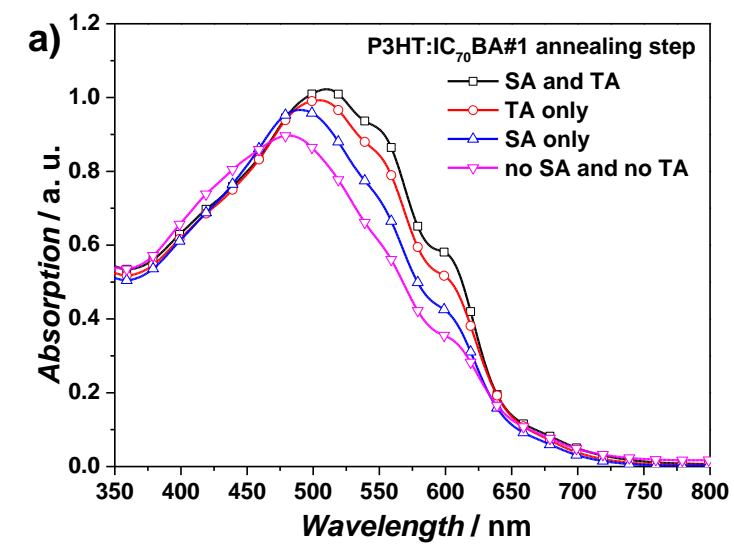




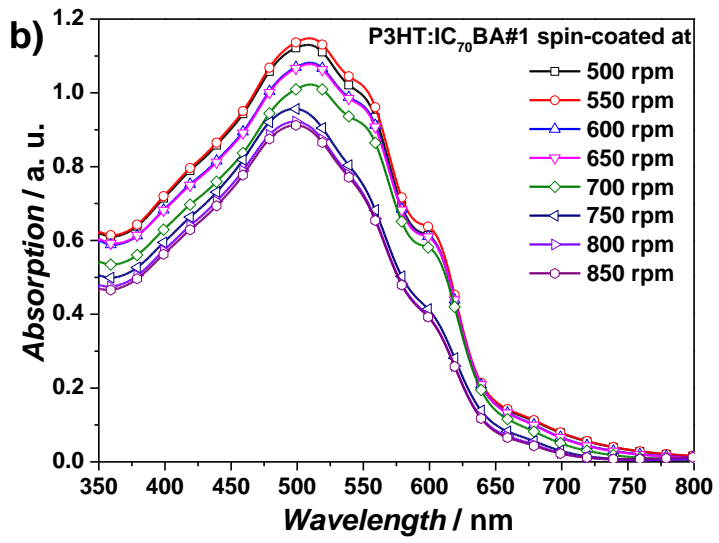

Figure 3. (a) UV-vis absorption characterization of $\mathrm{P} 3 \mathrm{HT}: \mathrm{IC}_{70} \mathrm{BA \# 1}$ layers depending on the annealing step (SA vs. TA) and (b) depending on the spin-coating speed during the fabrication process.

\subsection{Vertical distribution of the blend D-A volume fractions}

The morphology of the P3HT:IC $70 \mathrm{BA}$ can be understood by investigating the vertical distribution of the $\mathrm{P} 3 \mathrm{HT}$ and $\mathrm{IC}_{70} \mathrm{BA}$ volume fractions and their dependence on the fabrication conditions (SA and TA), by means of using spectroscopic ellipsometry (SE). The optical properties of the D-A layers are represented by the complex refractive index,

$\widetilde{n}(\omega)=n(\omega)+i k(\omega)$

and the complex pseudo-dielectric function,

$\langle\tilde{\varepsilon}(\omega)\rangle=\left\langle\varepsilon_{1}(\omega)\right\rangle+i\left\langle\varepsilon_{2}(\omega)\right\rangle$,

where $\omega$ is the photon energy. ${ }^{[49,51-53]}$

The measured $\langle\tilde{\varepsilon}(\omega)\rangle$ is examined using the modified Tauc-Lorentz (TL) oscillator model, described in detail in Supporting Section 7. The optical constants of the pristine $\mathrm{IC}_{70} \mathrm{BA \# 1}$ and P3HT (Figure S13 and S14) were determined in advance and were fixed during the analysis (Figure S15). The fitted parameters were then the volume fractions, \% Vol(P3HT)i and $\% \operatorname{Vol}\left(\mathrm{IC}_{70} \mathrm{BA \# 1}\right)_{\mathrm{i}}($ where $\mathrm{i}=$ top, bottom), and the blend layer thickness.

Identical evolution of the calculated volume fractions for two sets of P3HT:IC $70 \mathrm{BA \# 1}$ samples in the top and bottom regions of the blend layer with respect fabrication conditions is given in Figure 4a. As cast P3HT:IC 70 BA\#1 layers (No SA, No TA) show donor-enriched 
top regions (74\% P3HT content) and acceptor-enriched bottom regions (74\% $\mathrm{IC}_{70} \mathrm{BA \# 1}$ content). This D-A vertical distribution is significantly enhanced after a post deposition thermal annealing (No SA, $\left.10 \mathrm{~min} / 150^{\circ} \mathrm{C}\right)$. The $\% \mathrm{Vol}(\mathrm{P} 3 \mathrm{HT})_{\text {top }}$ and $\% \mathrm{Vol}\left(\mathrm{IC}_{70} \mathrm{BA \# 1}\right)_{\text {bottom }}$ reach $91 \%$, indicating an enrichment of the top regions with $\mathrm{P} 3 \mathrm{HT}$, while the $\mathrm{IC}_{70} \mathrm{BA \# 1}$ molecules are segregated towards the bottom. However, the unbalanced D-A distribution for No SA but TA $\left(10 \mathrm{~min} / 150^{\circ} \mathrm{C}\right) \mathrm{P} 3 \mathrm{HT}: \mathrm{IC}_{70} \mathrm{BA \# 1}$ layers consequently indicates a high phase separation of the blend components and low homogeneity in the vertical direction. The agglomeration of the $\mathrm{IC}_{70} \mathrm{BA \# 1}$ regio-isomers, realized during the evaporation of the blend solvent during the TA process, is mainly attributed to the different surface energies of P3HT (27.2 $\mathrm{mN} \mathrm{m}^{-1}$, Supporting Section 8) and IC $70 \mathrm{BA \# 1} \mathrm{(28.7} \mathrm{mN} \mathrm{m}^{-1}$, Figure S16). The component with the lower surface energy (P3HT) therefore has a higher concentration closer to the upper film surface, whereas the component with higher surface energy ( $\left.\mathrm{IC}_{70} \mathrm{BA \# 1}\right)$ accumulates closer to the high surface energy interface with the PEDOT:PSS $\left(69 \mathrm{mN} \mathrm{m}^{-1}\right.$, Figure S17), leading to a reduction in the free energy of the system.

Introducing the SA step drastically improves the intermixing characteristics of the BHJ. Compared to pristine films (No SA, No TA), $30 \mathrm{~min}$ of SA (30 min SA, No TA) leads to a more balanced vertical D-A distribution $($ Bottom $=54 \%$ IC $70 \mathrm{BA \# 1}$ and $46 \%$ P3HT; Top $=$ $64 \% \mathrm{P} 3 \mathrm{HT}$ and $\left.36 \% \mathrm{IC}_{70} \mathrm{BA \# 1}\right)$. In comparison, TA of the P3HT: $\mathrm{IC}_{70} \mathrm{BA \# 1}$ for $10 \mathrm{~min}$ at $90{ }^{\circ} \mathrm{C}$ does not provide a sufficient driving force for the blend to achieve a more thermodynamically favourable morphology. A further small but quantifiable improvement can be achieved after $10 \mathrm{~min} \mathrm{TA}$ at $150{ }^{\circ} \mathrm{C}$ or $170{ }^{\circ} \mathrm{C}: \% \mathrm{Vol}\left(\mathrm{IC}_{70} \mathrm{BA} \# 1\right)_{\text {bottom }}$ is increased to $60 \%$ and $62 \%$, while the $\% \operatorname{Vol}(\mathrm{P} 3 \mathrm{HT})_{\text {bottom }}$ is reduced to $40 \%$ and $38 \%$, respectively; $\% \operatorname{Vol}\left(\mathrm{IC}_{70} \mathrm{BA \# 1}\right)_{\text {top }}$ is $37 \%$ and $36 \%$, while $\% \mathrm{Vol}(\mathrm{P} 3 \mathrm{HT})_{\text {top }}$ reaches $63 \%$ and $64 \%$.

The results from the D-A vertical distribution characterization suggest that SA layers are less prone to TA alterations of the D-A volume fractions, compared to pristine films. Clearly, the 
two different procedures (SA and TA) seem to have the opposite effect on the vertical blend morphology, but a combination of both is required to achieve an interpenetrating D-A network with appropriately distributed volume fractions.
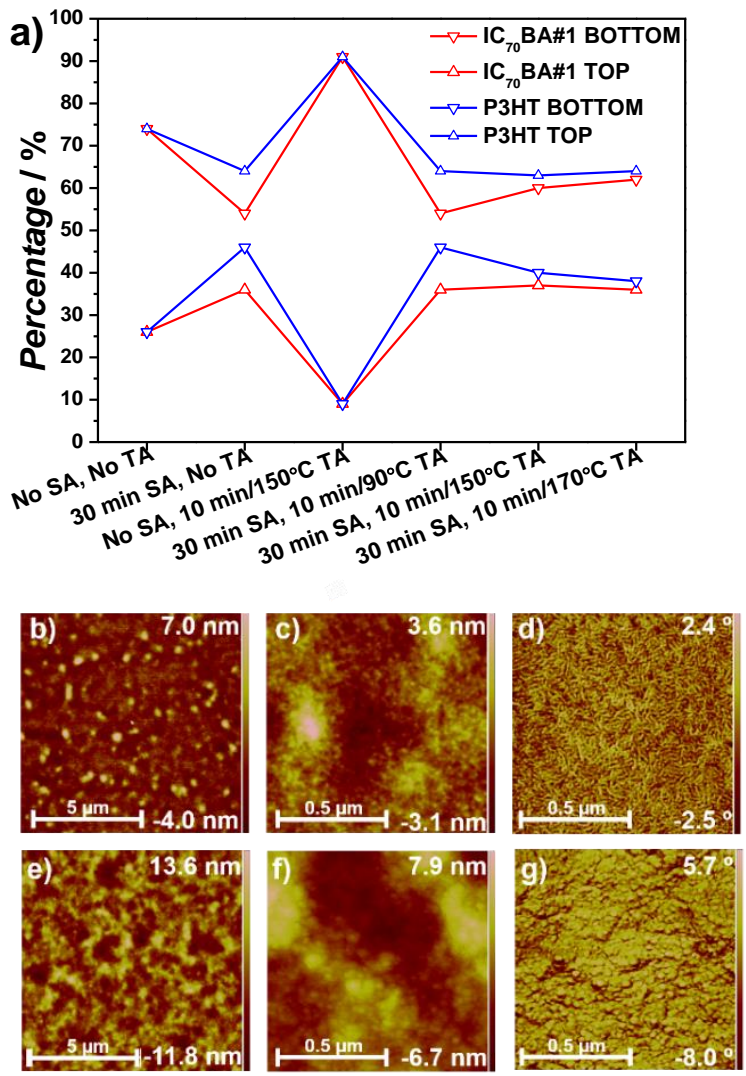

Figure 4. (a) Morphological characterization of $\mathrm{P} 3 \mathrm{HT}: \mathrm{IC}_{70} \mathrm{BA} \# 1$ layers with respect to the volume fraction of $\mathrm{P} 3 \mathrm{HT}$ and $\mathrm{IC}_{70} \mathrm{BA \# 1}$ in the bottom and top regions of two P3HT:IC ${ }_{70} \mathrm{BA \# 1}$ blend films as a function of the fabrication conditions (SA and TA), as calculated from the analysis of the measured $\langle\tilde{\varepsilon}(\omega)\rangle$ in the UV-Vis spectral region. b) AFM scans showing the effect of SA on the P3HT:IC 70 BA\#1 morphology. (b-d) Non-SA layers, (eg) layers subject to $30 \mathrm{~min}$ SA. (d) and (g) are the phase images of the topography scans in (c) and (f).

\subsection{P3HT:IC70BA topography}

Atomic force microscopy (AFM) analysis shows that non-SA P3HT:IC 70 BA\#1 layers do not form an interpenetrating D-A network, but instead form clusters with an average size of $304 \pm$ $172 \mathrm{~nm}$ (Figure 4b). On the other hand, after $30 \mathrm{~min}$ SA, different features are observable on the surface of the layer (Figure 4e). Non-SA films exhibit an average root mean square 
(RMS) surface roughness ( $\mathrm{R}_{\mathrm{RMS}}$ ) of $0.89 \mathrm{~nm}$, compared to rougher surfaces for the SA films $\left(\mathrm{R}_{\mathrm{RMS}}=2.25 \mathrm{~nm}\right)$.

Further insight into the morphology changes induced by SA can be obtained from the phase images (Figure 4d and 4g). Without SA, the surface of the blend is predominantly P3HT nanofibres, and it appears that the $\mathrm{IC}_{70} \mathrm{BA \# 1}$ has settled to the bottom of the $\mathrm{BHJ}$ layer, which is in accordance with the SE analysis. In contrast, after SA a different film morphology is observed consisting of P3HT nanofibres surrounded by clusters of the $\mathrm{IC}_{70} \mathrm{BA \# 1}$ regioisomers, indicating that an appropriate phase separation is formed. Additionally, analysing the feature sizes on the film surface shows average values of $28.3 \mathrm{~nm}$, which is in good agreement with previously reported values. ${ }^{[27]}$

\subsection{P3HT:IC70BA device characterization}

The device characteristics crucially depend on the annealing step of the P3HT:IC ${ }_{70} \mathrm{BA \#} 1$ blend during the fabrication process as shown in Figure 5a and Table 1. In an excellent agreement with the UV-Vis, SE, and AFM characterization, best performing devices are subjected to both SA and TA, which induce high blend crystallinity, appropriate BHJ nonomorphology with closely packed regio-isomeric domains, reducing the hopping distance for electron transport. ${ }^{[10]}$ Hence, better electronic coupling for electron transfer and higher electron mobilities are achieved. ${ }^{[54]}$ This is confirmed by the high average $\mathrm{J}_{\mathrm{SC}}, \mathrm{FF}$, and PCE $\left(10.03 \mathrm{~mA} \mathrm{~cm}^{-2}, 69.7 \%\right.$, and $\left.5.97 \%\right)$ resulting from the balanced vertical D-A material distribution, shown by the SE data. Slightly lower average PSCs characteristics were measured for SA only devices ( $\mathrm{J}_{\mathrm{SC}}, \mathrm{FF}$, and PCE of $9.93 \mathrm{~mA} \mathrm{~cm}^{-2}, 65.4 \%$, and 5.37\%). We ascribe this to comparable blend characteristics in terms of vertical D-A fractions distribution and blend morphology, however the missing TA step reduces the slow melting transition and re-arrangement of the $\mathrm{IC}_{70} \mathrm{BA \# 1}$ lattice, processes evident from the phase transition behaviour of $\mathrm{IC}_{70} \mathrm{BA \# 1}$ for temperatures above $90{ }^{\circ} \mathrm{C}$. The molecular packing is altered and there are less segregated $\mathrm{IC}_{70} \mathrm{BA \# 1}$ molecules captured by the self-organized polymeric network 
formed by P3HT crystallites. As a result, the photo-generated charge carrier transport within the P3HT:IC $70 \mathrm{BA \# 1}$ blend is impeded, and charge carrier recombination processes reduce the device FF.
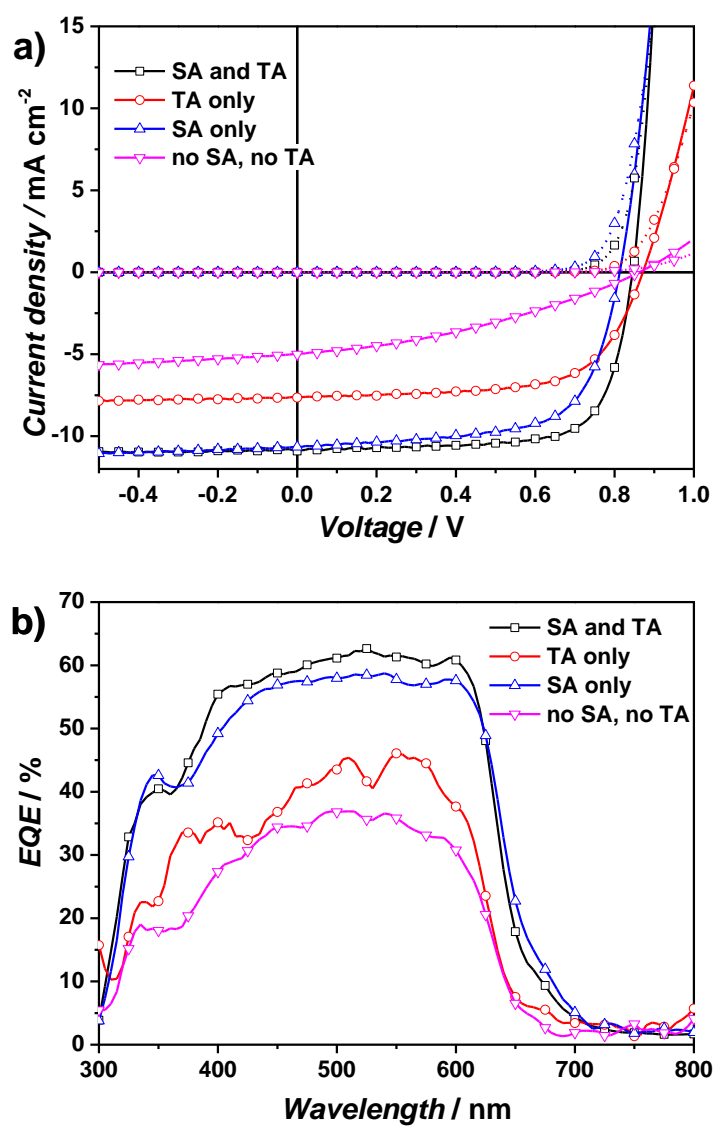

Figure 5. (a) J-V characteristics of P3HT: $\mathrm{IC}_{70} \mathrm{BA \# 1}$ PSCs under illumination of AM1.5G $\left(100 \mathrm{~mW} \mathrm{~cm}^{-2}\right)$ (solid lines) and in the dark (dotted lines) for different annealing conditions. (b) corresponding EQE spectra.

Table 1. Performance characteristics of multiple P3HT:IC ${ }_{70} B A$ PSCs $(n=15)$ fabricated using $\mathrm{IC}_{70} \mathrm{BA \# 1} 1$ under different annealing conditions. For comparison the characteristics of $\mathrm{IC}_{70} \mathrm{BA \# 2}$ devices, fabricated under identical SA and TA optimized conditions, are also included.

\begin{tabular}{ccccccc}
\hline Batch & $\begin{array}{c}\text { Annealing } \\
\text { step }\end{array}$ & $\mathrm{V}_{\text {oc }}[\mathrm{V}]$ & $\begin{array}{c}\mathrm{J}_{\mathrm{SC}} \\
{\left[\mathrm{mA} \mathrm{cm}^{-2}\right]}\end{array}$ & $\mathrm{FF}[\%]$ & $\begin{array}{c}\text { Average PCE } \\
{[\%]}\end{array}$ & $\begin{array}{c}\text { Peak PCE } \\
{[\%]}\end{array}$ \\
\hline$\# 1$ & SA and TA & $0.85 \pm 0.01$ & $10.03 \pm 0.46$ & $69.7 \pm 3.6$ & $5.97 \pm 0.40$ & 6.74 \\
& TA only & $0.86 \pm 0.01$ & $7.40 \pm 0.32$ & $55.7 \pm 9.4$ & $3.58 \pm 0.76$ & 4.34 \\
& SA only & $0.83 \pm 0.00$ & $9.93 \pm 0.54$ & $65.4 \pm 0.6$ & $5.37 \pm 0.76$ & 5.59 \\
& no SA or TA & $0.87 \pm 0.01$ & $4.83 \pm 0.18$ & $33.7 \pm 1.9$ & $1.42 \pm 0.12$ & 1.55 \\
$\# 2$ & SA and TA & $0.80 \pm 0.02$ & $4.31 \pm 0.95$ & $51.4 \pm 5.3$ & $1.76 \pm 0.37$ & 2.16 \\
\hline
\end{tabular}

When P3HT:IC70BA\#1 layers are subject to TA only, the output characteristics of the devices are further reduced as shown in Table 1. Lower $\mathrm{J}_{\mathrm{SC}}$ and FF values are evident, originating 
from a higher D-A blend phase separation and lower homogeneity in the vertical direction

(Figure 4a, P3HT enrichment of the top regions and $\mathrm{IC}_{70} \mathrm{BA \# 1}$ settlement at the bottom of the layer). The lowest device characteristics were observed when no SA and no TA was carried out, with a measured average $\mathrm{J}_{\mathrm{SC}}$ and PCE of $4.83 \pm 0.18 \mathrm{~mA} \mathrm{~cm}^{-2}$ and $1.42 \pm 0.12 \%$. This is due to lower light absorption and less self-organization and crystallization of the P3HT:IC70BA\#1 blend evident from the UV-vis characterization. We believe that these adverse device characteristics have a direct connection with the disadvantageous molecular

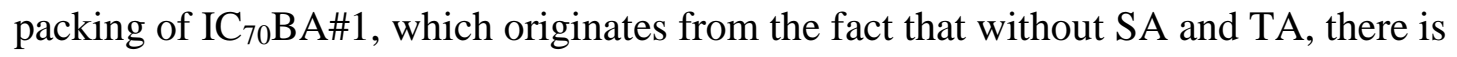
insufficient time and temperature for rearrangement and slow melting of the $\mathrm{IC}_{70} \mathrm{BA \# 1}$ regioisomers, in order to form an appropriate BHJ morphology and improve the exciton separation yields and free charge transfer processes.

To tune the BHJ thickness, P3HT:IC 70 BA\#1 PSCs produced from 40, 42, and $45 \mathrm{mg} \mathrm{mL}^{-1}$ solutions were characterized as shown in Figure S18 and summarized in Table S3. In addition, to achieve the optimal device characteristics, the spin-coating speed for the P3HT:IC $70 \mathrm{BA \# 1}$ layer was altered from 500 to $850 \mathrm{rpm}$ (Figure S19, Table S4). Interestingly, there is a continuous decrease of the $\mathrm{J}_{\mathrm{SC}}$ values, related to the BHJ thickness (Figure S12), from 10.05 $\mathrm{mA} \mathrm{cm}^{-2}$ (Figure S19a; $500 \mathrm{rpm}$ devices; thickness of $238.3 \mathrm{~nm} \pm 3.86 \mathrm{~nm}$ ) down to $6.10 \mathrm{~mA}$ $\mathrm{cm}^{-2}$ (Figure S19b; $850 \mathrm{rpm}$ devices; thickness of $175.3 \mathrm{~nm} \pm 4.11 \mathrm{~nm}$ ). Based on the UV-vis data in Figure $\mathbf{3 b}$, we summarize that this $\mathrm{J}_{\mathrm{SC}}$ decrease, is dominated by the rapid drying of the P3HT:IC $70 \mathrm{BA \# 1}$ layer during the spin-coating process, leading to reduced film crystallinity and unbalanced vertical D-A material distribution. This additionally lowers the FF and PCE for the 850 rpm devices (55.75\% and 2.98\%), when compared to the other PSCs. The highest average PCE values of $5.97 \pm 0.40 \%$ and $5.95 \pm 0.29 \%$ were measured for devices fabricated at 600 and $650 \mathrm{rpm}$, respectively. This originates form a balanced charge carrier transport as evidenced by the high average FF values of $69.7 \%$ and $71.3 \%$, respectively. The best performing P3HT: $\mathrm{IC}_{70} \mathrm{BA \# 1}$ device exhibits $\mathrm{V}_{\mathrm{OC}}$ of $0.86 \mathrm{eV}, \mathrm{J}_{\mathrm{SC}}$ of 
$10.91 \mathrm{~mA} \mathrm{~cm}^{-2}$, and a FF of $72 \%$, leading to a peak PCE of $6.74 \%$. It is worth noting, that this PCE value represents a record PCE measured for such large device active area $\left(0.43 \mathrm{~cm}^{2}\right)$, when compared to average reported PCEs of approx. $4.5 \%$ for devices areas less than $0.1 \mathrm{~cm}^{2}$, respectively.

To test the importance of the regio-isomeric mixture of $\mathrm{IC}_{70} \mathrm{BA}$ on the molecular packing of the BHJ and hence device PCE, we applied the tailored fabrication conditions found for $\mathrm{IC}_{70} \mathrm{BA \# 1}(5,2$, and 12 o'clock regio-isomers with a distribution of $22 \%, 43 \%$, and $35 \%$, see Figure $\mathrm{S} 1$ and Table S1), onto $\mathrm{IC}_{70} \mathrm{BA} \# 2$, which exhibits a different 5, 2, and 12 o'clock regio-isomeric distribution $(16 \%, 36 \%$, and 48\%, see Figure S2 and Table S2). Figure 6a and Table 1 show the comparison of the best performing device from each $\mathrm{IC}_{70} \mathrm{BA}$ batch, fabricated under identical conditions.
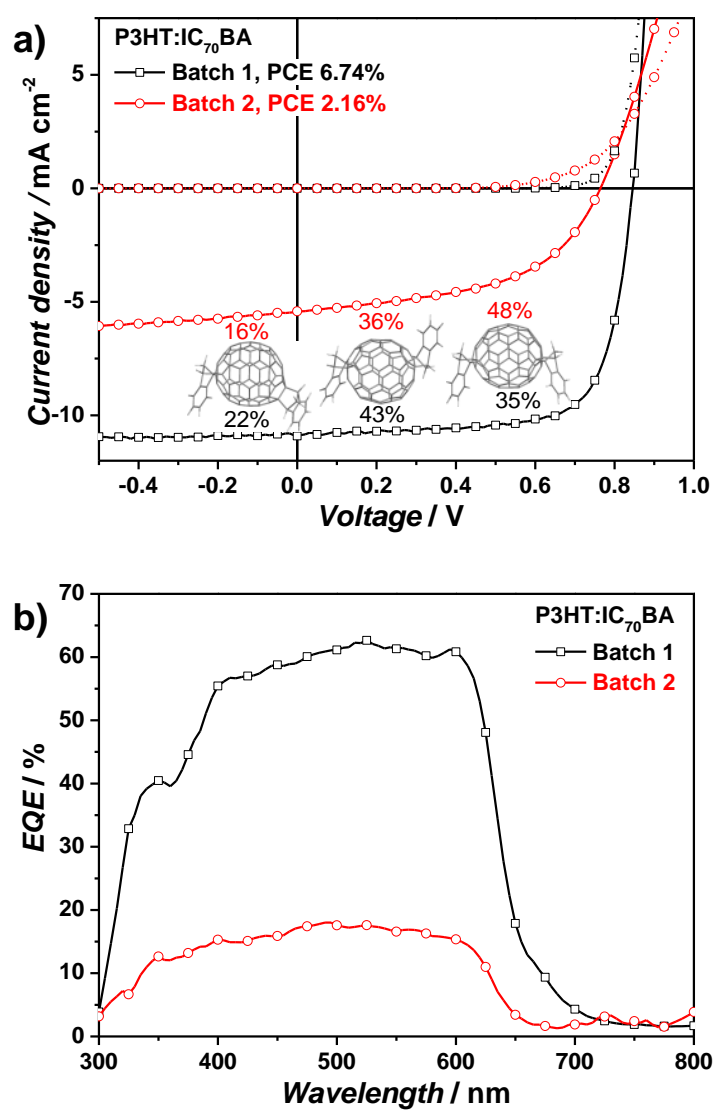

Figure 6. (a) J-V characteristics of P3HT:IC 70 BA PSCs under illumination of AM1.5G (100 $\mathrm{mW} \mathrm{cm}{ }^{-2}$ ) (solid lines) and in the dark (dotted lines) for two different $\mathrm{IC}_{70} \mathrm{BA}$ batches. (b) corresponding EQE spectra. 
It is known that BHJ blends of the 2 o'clock regio-isomer in combination with P3HT deliver the highest device PCE. ${ }^{[36]}$ This is supported by the fact that the 2 o'clock regio-isomer exhibits the shortest distance between the "pole" carbon atom and the indene addend at the opposite pole ( $8.36 \AA$ A, Figure S6), which can be related to reduced hopping distances and improved electron conduction due to closely packed fullerene-fullerene molecules improving the electron mobility and carrier transport properties. ${ }^{[10,54]}$ However, based on our results for $\mathrm{IC}_{70} \mathrm{BA \# 1}$ shown in Figure 5a, comparable high PCEs are also possible for a mixture of $\mathrm{IC}_{70} \mathrm{BA}$ regio-isomers, if a predominantly 2 o'clock regio-isomeric content is present, and appropriate device fabrication conditions are used. Yet, the ratio of the remaining regioisomer distribution needs to be considered and can be crucial for the device performance. As shown in Figure 6a, despite a close 2 o'clock distribution for the $\mathrm{IC}_{70} \mathrm{BA \# 1}$ and $\mathrm{IC}_{70} \mathrm{BA \# 2}$ ( $43 \%$ vs. $36 \%$ ), a variation of the 5 and 12 o'clock regio-isomer ratio (22\% and $35 \%$ vs. $16 \%$ and $48 \%$ ) is sufficient to reduce the device $\mathrm{J}_{\mathrm{SC}}$ and PCE from $10.91 \mathrm{~mA} \mathrm{~cm}^{-2}$ and $6.74 \%$ to $5.42 \mathrm{~mA} \mathrm{~cm}^{-2}$ and $2.16 \%$. It should be noted that $\mathrm{IC}_{70} \mathrm{BA \# 2}$ exhibits a significantly larger amount of the 12 o'clock regio-isomer. It is believed that the highly symmetric nature of the indene addends for the 12 o'clock regio-isomer impedes the $\pi$ - $\pi$ stacking of the P3HT molecules, due to high crystallite formation within the regio-isomeric molecules, disturbing the intermolecular ordering and charge transfer properties of the donor phase. This, on the other hand, can directly related to a reduced charge carrier mobilities and exciton dissociation yields, lowering the device $\mathrm{J}_{\mathrm{SC}}, \mathrm{FF}$, and PCE. ${ }^{[10,54]}$ These assumptions are additionally supported by the observations made for the isolated 12 o'clock regio-isomer, which was visibly less soluble, and solutions were less stable, and prone to larger cluster aggregation, compared to the other regio-isomers.

To ensure that the $\mathrm{J}_{\mathrm{SC}}$ measured under irradiation by the solar simulator is within an acceptable error, we also measured the external quantum efficiency (EQE) spectra for the devices (Figure 5b and $\mathbf{6 b}$ ). It can be seen in Figure 5b that the corresponding EQE spectra 
of devices with a P3HT:IC ${ }_{70} \mathrm{BA \# 1}$ BHJ subjected to SA and TA reach about $60 \%$ for the wavelengths $450-600 \mathrm{~nm}$. Slightly lower EQE values were measured for SA only BHJs. Layers fabricated with TA only or without any annealing step show the lowest EQE values pointing to strongly reduced exciton dissociation rates and charge carrier transport processes. This assumption is further strengthened after comparison with the EQE spectra between $\mathrm{IC}_{70} \mathrm{BA \# 1}$ and $\mathrm{IC}_{70} \mathrm{BA \# 2}$, shown in Figure $\mathbf{6 b}$, where an EQE of only about $15 \%$ was measured for the devices fabricated with $\mathrm{IC}_{70} \mathrm{BA \# 2}$.

\section{Conclusion}

For this study, we show a thorough characterization of commercial $\mathrm{IC}_{70} \mathrm{BA}$ samples. After conducting HPLC, UV-vis, ${ }^{1} \mathrm{H}$ NMR, and ${ }^{13} \mathrm{C}$ NMR characterization of two different $\mathrm{IC}_{70} \mathrm{BA}$ batches, we found different isomeric distributions of the 2, 5, and 12 o'clock regio-isomers within each batch. In a case study investigating the thermal stability and phase transition properties of $\mathrm{IC}_{70} \mathrm{BA}$ batch\#1 and in its blend with $\mathrm{P} 3 \mathrm{HT}$, we postulate the presence of morphological changes in the D-A blend, altering the phase separation of the BHJ. To the best of our knowledge, we are the first to report the use of SE as a non-destructive characterization technique to investigate the volume fraction distribution of $\mathrm{P} 3 \mathrm{HT}$ and $\mathrm{IC}_{70} \mathrm{BA}$ blends. Taking the data from the SE in conjunction with UV-vis, TGA, DSC, and AFM data, we demonstrate that there is a difference in the crystallization transformation of the blend between P3HT and the regio-isomeric mixture of $\mathrm{IC}_{70} \mathrm{BA}$ depending on the fabrication process used. This affects the molecular packing of the photoactive layer and therefore the device PCE. Based on these findings, we have determined the optimal fabrication conditions for the production of P3HT:IC 70 BA PSCs with PCEs above $6.7 \%$ for a particular regio-isomeric distribution. The sensitivity of the spatial molecular packing of BHJs between donor materials and isomeric fullerene acceptors is illustrated with different isomeric fractions of $\mathrm{IC}_{70} \mathrm{BA}$. As such, we demonstrate how the PSC characteristics can be improved in the future based on an 
understanding of the formation kinetics of the BHJ phase separation, which allows for the fabrication of highly efficient PCSs.

We also show that despite a high $\mathrm{IC}_{70} \mathrm{BA}$ material purity of above $99 \%$ for different material batches, the crucial factor determining the PCE is the variation of the regio-isomeric ratio of $\mathrm{IC}_{70} \mathrm{BA}$ when blended with $\mathrm{P} 3 \mathrm{HT}$. The device performance can be optimized after tailoring the regio-isomeric ratio in the mixture or utilizing individual $\mathrm{IC}_{70} \mathrm{BA}$ isomers, which is currently under investigation. The outcomes of this study provide a better understanding of the D-A phase formation and separation, and pave the way towards a fundamental understanding of the spatial molecular packing of numerous BHJ materials systems (including ternary BHJs), in which fullerene derivatives with isomeric properties are used as electron accepting materials.

\section{Experimental Section}

Materials: Regioregular poly(3-hexylthiophene) (P3HT 4002-EE, Rieke Metals Inc.) and indene- $\mathrm{C}_{70}$-bisadduct ( $\mathrm{IC}_{70} \mathrm{BA}$, 1-Material - Organic Nano Electronic) were used as the D-A components in a solution of 1,2-dichlorobenzene (o-DCB, 99\%). Poly(3,4ethylenedioxythiophene) poly-(styrene sulfonate) (PEDOT-PSS Clevios P VP AI 4083, Heraeus Holding $\mathrm{GmbH}$ ) was used as the hole transport layer and 2,9-dimethyl-4,7-diphenyl1,10-phenanthroline (BCP or bathocuproine, Luminescence Technology Corp.) was used as the electron transport layer.

Device fabrication: Pre-patterned glass substrates (15 $\Omega \mathrm{sq}^{-1}$., Luminescence Technology Corp.) were sonicated sequentially in decon 90 water, deionized (DI) water, acetone and methanol for $5 \mathrm{~min}$ each, followed by an oxygen plasma treatment $(5 \mathrm{~min}, 100 \mathrm{~W}, 15 \mathrm{sccm} \mathrm{O}$, Emitech K1050X plasma cleaner). PEDOT:PSS films were produced by spin-coating (60 s at $4000 \mathrm{rpm}$ ) from a filtered solution under ambient conditions, and subsequently annealed for 
30 min at $150{ }^{\circ} \mathrm{C}$. Equal material weight concentrations of $\mathrm{P} 3 \mathrm{HT}$ and $\mathrm{IC}_{70} \mathrm{BA}(20,21$ or 22.5 $\mathrm{mg})$ were mixed into o-DCB (1 mL, 1:1 ratio) and dissolved for at least 24 hours under vigorous stirring at room temperature. The $\mathrm{P} 3 \mathrm{HT}: \mathrm{IC}_{70} \mathrm{BA}$ solution was then spin-coated on top of the PEDOT:PSS film, initially for $80 \mathrm{~s}$ at speed of $500-850 \mathrm{rpm}$, followed by a second step for $5 \mathrm{~s}$ at $1000 \mathrm{rpm}$. The wet film was either allowed to quick dry in approx. $5 \mathrm{~s}$ under inert atmosphere conditions at room temperature, or was covered with a petri dish $(60 \mathrm{~mm}$ diameter, $15 \mathrm{~mm}$ height) for $30 \mathrm{~min}$ to enable slow drying of the film. Thermal annealing (10 min, $\left.90-50{ }^{\circ} \mathrm{C}\right)$ was also carried out when required. For PSC device fabrication, BCP (2-3 $\mathrm{nm}$ ) and aluminium $(75 \mathrm{~nm})$ were evaporated through a shadow mask, at pressures below $3 \mathrm{x}$ $10^{-6}$ mbar. The Al/ITO electrodes overlap within the devices was $0.90 \mathrm{~cm}^{2}$. All fabrication steps after the PEDOT:PSS deposition were performed in a nitrogen-filled glove box.

Solid films characterization: Optical characterization (Varian Cary 5000 UV-vis-NIR spectrophotometer) was undertaken relative to a glass reference in the wavelength range 300 $900 \mathrm{~nm}$ (scan rate $600 \mathrm{~nm} \mathrm{~min}{ }^{-1}$ and a sampling interval of $1 \mathrm{~nm}$ ). Film thickness measurements were conducted using a Dektak 8 profilometer. Surface topography characterization was performed using a Veeco Dimension 3000 AFM system in tapping mode on 3 different locations on the sample surface. Thermogravimetric analysis (TGA, TA Q500 thermogravimetric analyser) was conducted from room temperature $\left(27^{\circ} \mathrm{C}\right)$ to $800{ }^{\circ} \mathrm{C}$ or $900{ }^{\circ} \mathrm{C}$ with a heating rate of $10{ }^{\circ} \mathrm{C} \mathrm{min}^{-1}$ and a $\mathrm{N}_{2}$ sample purge flow $\left(60 \mathrm{~mL} \mathrm{~min}^{-1}\right)$. Differential scanning calorimetry (DSC, TA Q1000 DSC) was undertaken using aluminium weighing pans, with heating and cooling rates of $10{ }^{\circ} \mathrm{C} \mathrm{min}^{-1}$ and a $\mathrm{N}_{2}$ purge flow $(50 \mathrm{~mL}$ $\left.\min ^{-1}\right)$.

$I C_{70} B A$ characterization: High performance liquid chromatography (HPLC) spectra were obtained on a Japan Analytical Industry (JAI) LC-9103 Recycling Preparative HPLC with a 
modular Hitachi L-7150 pump and JAI UV Detector 3702. The following parameters were used: Cosmosil@ Buckyprep-M 20.0 mm ID x $250 \mathrm{~mm}$ column, toluene solvent, $16 \mathrm{ml} \mathrm{min}{ }^{-1}$ flow rate, and $312 \mathrm{~nm}$ absorption. Mass spectra (MS) of the fractions were obtained on a Bruker microflex ${ }^{\mathrm{TM}}$ LT using matrix-assisted laser desorption/ionization time-of-flight mass spectrometry (MALDI-TOF MS) analysis. Negative ionization was employed and trans-2-[3(4-t-butyl-phenyl)-2-methyl-2-propenylidene] malononitrile (DCTB) was used as the matrix material. UV-vis spectra of the fractions, isolated by HPLC, were obtained on a Jasco V-570 Spectrophotometer in toluene. Samples for proton nuclear magnetic resonance ( ${ }^{1} \mathrm{H}$ NMR) spectroscopy were dried in vacuo for at least 24 hours before being dissolved in deuterated chloroform (CDCl3). All spectra were obtained on a $400 \mathrm{MHz}$ Bruker AVIII400 spectrometer. The optical properties and the morphology of the P3HT: $\mathrm{IC}_{70} \mathrm{BA \# 1}$ samples (two sets of samples) have further been investigated using a phase modulated Spectroscopic Ellipsometer (Horiba) from near infrared to far UV $(0.7-6.5 \mathrm{eV})$ with steps of $20 \mathrm{meV}$ with $70^{\circ}$ angle of incidence. The optical response of the substrate layers (glass and ITO) was measured followed by the measurement and calculation of the optical properties of pristine P3HT and $\mathrm{IC}_{70} \mathrm{BA}$ materials (see S7 in Supplementary Information) was performed in order to be used as reference for the analysis of the $<\varepsilon(\omega)>$ of the P3HT: $\mathrm{IC}_{70} \mathrm{BA}$ blends. Contact angle (CA) measurements (CAM 200, KSV Instruments Ltd.) were conducted using a static drop technique with a deionized (DI) water droplet $(5 \mu \mathrm{l})$ and a surface tension of $72.8 \mathrm{mN} \mathrm{m}^{-1}$. Surface energies were calculated using the relation reported by Chibowski et al. ${ }^{[55]}$. Cyclic voltammograms of P3HT:IC $70 \mathrm{BA}$ blend films deposited onto ITO electrodes were performed in $0.1 \mathrm{M} \mathrm{NBu}_{4} \mathrm{PF}_{6} / \mathrm{MeCN}$ and $0.1 \mathrm{M} \mathrm{NHex}_{4} \mathrm{PF}_{6} / \mathrm{MeCN}$ in a gas tight three electrode cell (counter electrode: Pt plate; pseudo-reference electrode: $\mathrm{Ag}$ wire coated with an $\mathrm{AgCl}$ layer, directly immersed into the electrolyte solution) under argon atmosphere at room temperature. The I-E curves were recorded with a scan rate of $20 \mathrm{mV} \mathrm{s}^{-1}$. Oxidation and reduction potential cycles were recorded separately. For the calculation of the LUMO and HOMO energy values 
the half wave potential $\left(\mathrm{E}_{1 / 2}\right)$ of the first fullerene reduction and the onset potential of the P3HT oxidation (p-doping) was used, respectively. Energy levels were calculated assuming that the $\mathrm{Fc} / \mathrm{Fc}^{+}$couple is located at $-5.1 \mathrm{eV}$ in the Fermi scale. ${ }^{[56]}$

Device characterization: Current-voltage (I-V) characterization was conducted in ambient atmosphere, without encapsulation, using a four-point probe configuration (Keithley 2400 source measurement apparatus). An Abet Technologies 10500 solar simulator (class AAB) at AM 1.5 G, calibrated with a silicon reference cell (PV Measurements, Inc. 20 x $20 \mathrm{~mm}$ ) to $100 \mathrm{~mW} \mathrm{~cm}{ }^{-2}$, was used to illuminate the devices. For more accurate definition of the illuminated area, an aperture of $0.43 \mathrm{~cm}^{2}$ was used. For external quantum efficiency (EQE) measurements, a Bentham Instruments PVE 300, with 1-Sun light bias, was utilized in the wavelength range from $300 \mathrm{~nm}$ to $800 \mathrm{~nm}$ ( $5 \mathrm{~nm}$ step).

\section{Supporting Information}

Supporting Information is available from the Wiley Online Library or from the author.

\section{Acknowledgements}

The authors would like to acknowledge Dr Edward New, Dr K. D. G. Imalka Jayawardena, Dr Adrian Ruff, Dr Michail Terzidis and Dr Ian Hamerton for fruitful discussions and Violeta Doukova for conducting the TGA and DSC characterization. We gratefully acknowledge support received from the European Commission 7th framework programme SMARTONICS (Grant Agreement Number 310229).

Received: ((will be filled in by the editorial staff))

Revised: ((will be filled in by the editorial staff)) Published online: ((will be filled in by the editorial staff)) 
[1] J.-D. Chen, C. Cui, Y.-Q. Li, L. Zhou, Q.-D. Ou, C. Li, Y. Li and J.-X. Tang, Adv. Mater. 2015, 27, 1035.

[2] J. Huang, J. H. Carpenter, C.-Z. Li, J.-S. Yu, H. Ade and A. K.-Y. Jen, Adv. Mater. 2016, $28,967$.

[3] Z. Zheng, S. Zhang, J. Zhang, Y. Qin, W. Li, R. Yu, Z. Wie and J. Hou, Adv. Mater. 2016, $28,5133$.

[4] Q. Wan, X. Guo, Z. Wang, W. Li, B. Guo, W. Ma, M. Zhang and Y. Li, Adv. Funct. Mater. 2016, 26, 6635.

[5] K. D. G. I. Jayawardena, L. J. Rozanski, C. A. Mills and S. R. P. Silva, Nat. Photon. 2015, 9, 207.

[6] M. J. Beliatis, K. K. Gandhi, L. J. Rozanski, R. Rhodes, L. McCafferty, M. R. Alenezi, A. S. Alshammari, C. A. Mills, K. D. G. I. Jayawardena, S. J. Henley and S. R. P. Silva, Adv. Mater. 2013, 26, 2078.

[7] N. Li, P. Kubis, K. Forberich, T. Ameri, F. C. Krebs and C. J. Brabec, Sol. Energy Mater. Sol. Cells 2013, 120, 701.

[8] L. Lucera, F. Machui, P. Kubis, H. D. Schmidt, J. Adams, S. Strohm, T. Ahmad, K. Forberich, H.-J. Egelhaaf and C. J. Brabec, Energy Environ. Sci. 2016, 9, 89.

[9] Y. Zhang, J. Griffin, N. W. Scarratt, T. Wang and D. G. Lidzey, Prog. Photovolt: Res. Appl. 2016, 24, 275.

[10] H. K. H. Lee, Z. Li, I. Constantinou, F. So, S. W. Tsang and S. K. So, Adv. Energy Mater. 2014, 4, 1614.

[11] K. Tremel and S. Ludwigs, in Advances in Polymer Science, S. Ludwigs, Springer Berlin Heidelberg, 2014, 265, 39.

[12] Y. Kim, S. Cook, S. M. Tuladhar, S. A. Choulis, J. Nelson, J. R. Durrant, D. D. C. Bradley, M. Giles, I. McCulloch, C.-S. Ha and M. Ree, Nat. Mater. 2006, 5, 197. 
[13] J. E. Carlé, T. R. Andersen, M. Helgesen, E. Bundgaard, M. Jørgensen and F. C. Krebs, Sol. Energy Mater. Sol. Cells 2013, 108, 126.

[14] J. Y. Oh, M. Shin, T. I. Lee, W. S. Jang, Y.-J. Lee, C. S. Kim, J.-W. Kang, J.-M. Myoung, H. K. Baik and U. Jeong, Macromolecules 2013, 46, 3534.

[15] M. T. Dang, L. Hirsch, G. Wantz and J. D. Wuest, Chem. Rev. 2013, 113, 3734.

[16] Z. Xu, L.-M. Chen, G. Yang, C.-H. Huang, J. Hou, Y. Wu, G. Li, C.-S. Hsu and Y. Yang, Adv. Funct. Mater. 2009, 19, 1227.

[17] Z. Hu, J. Zhang and Y. Zhu, Appl. Phys. Lett. 2013, 102, 043307.

[18] G. Li, V. Shrotriya, J. Huang, Y. Yao, T. Moriarty, K. Emery and Y. Yang, Nat. Mater. $\mathbf{2 0 0 5}, 4,864$.

[19] W. Ma, C. Yang, X. Gong, K. Lee and A. J. Heeger, Adv. Funct. Mater. 2005, 15, 1617.

[20] M. C. Scharber, D. Muehlbacher, M. Koppe, P. Denk, C. Waldauf, A. J. Heeger and C. J. Brabec, Adv. Mater. 2006, 18, 789.

[21] M. T. Dang, L. Hirsch and G. Wantz, Adv. Mater. 2011, 23, 3597.

[22] L. J. A. Koster, V. D. Mihailetchi and P. W. M. Blom, Appl. Phys. Lett. 2006, 88, 093511.

[23] Y. He and Y. Li, Phys. Chem. Chem. Phys. 2011, 13, 1970.

[24] Y. He, G. Zhao, B. Peng and Y. Li, Adv. Funct. Mater. 2010, 20, 3383.

[25] Y. He, H.-Y. Chen, J. Hou and Y. Li, J. Am. Chem. Soc. 2010, 132, 1377.

[26] D. Angmo, M. Bjerring, N. C. Nielsen, B. C. Thompson and F. C. Krebs, J. Mater.

Chem. C 2015, 3, 5541.

[27] X. Fan, S. Li, S. Guo and G. Fang, J. Phys. D: Appl. Phys. 2013, 46, 055502.

[28] X. Guo, C. Cui, M. Zhang, L. Huo, Y. Huang, J. Hou and Y. Li, Energy Environ. Sci. 2012, 5, 7943. 
[29] A. M. Nardes, A. J. Ferguson, J. B. Whitaker, B. W. Larson, R. E. Larsen, M. Klára, P.

A. Graf, O. V. Boltalina, S. H. Strauss and N. Kopidakis, Adv. Funct. Mater. 2012, 22, 4115.

[30] G. Zhao, Y. He and Y. Li, Adv. Mater. 2010, 22, 4355.

[31] M. Jørrgensen, J. E. Carlé, R. R. Søndergaard, M. Lauritzen, N. A. Dagnæs-Hansen, S.

L. Byskov, T. R. Andersen, T. T. Larsen-Olsen, A. P. L. Böttiger, B. Andreasen, L. Fu, L.

Zuo, Y. Liu, E. Bundgaard, X. Zhan, H. Chen and F. C. Krebs, Sol. Energy Mater. Sol. Cells 2013, $119,84$.

[32] A. K. Pandey, J. M. Nunzi, B. Ratier and A. Moliton, Phys. Lett. A 2008, 372, 1333.

[33] L. J. Rozanski, C. T. G. Smith, K. K. Gandhi, M. J. Beliatis, G. D. M. R. Dabera, K. D.

G. I. Jayawardena, A. A. D. T. Adikaari, M. J. Kearney and S. R. P. Silva, Sol. Energy Mater. Sol. Cells 2014, 130, 513.

[34] F. L. M. Sam, M. A. Razali, K. D. G. I. Jayawardena, C. A. Mills, L. J. Rozanski, M. J. Beliatis and S. R. P. Silva, Org. Electron. 2014, 15, 3492.

[35] L. Hu, R. Cui, H. Huang, G. Lin, X. Guo, S. Yang, Y. Lian, J. Dong and B. Sun, J. Nanosci. Nanotechnol. 2015, 15, 5285.

[36] W. W. H. Wong, J. Subbiah, J. M. White, H. Seyler, B. Zhang, D. J. Jones and A. B. Holmes, Chem. Mater. 2014, 26, 1686.

[37] F. Zhao, X. Meng, Y. Feng, Z. Jin, Q. Zhou, H. Li, L. Jiang, J. Wang, Y. Li and C. Wang, J. Mater. Chem. A 2015, 3, 14991.

[38] B. Zhang, J. Subbiah, D. J. Jones and W. W. H. Wong, Beilstein J. Org. Chem. 2016, $12,903$.

[39] K. K. Gandhi, A. Nejim, M. J. Beliatis, C. A. Mills, S. J. Henley and S. R. P. Silva, J. Photon. Energy 2015, 5, 057007.

[40] S. Han, Z. Fei, K. D. G. I. Jayawardena, M. J. Beliatis, Y.-B. Hahn, A. A. D. T. Adikaari, M. J. Heeney and S. R. P. Silva, Thin Solid Films 2015, 576, 38. 
[41] K. D. G. I. Jayawardena, L. J. Rozanski, C. A. Mills, M. J. Beliatis, N. A. Nismy and S. R. P. Silva, Nanoscale 2013, 5, 8411.

[42] M. J. van Eis, R. J. Alvarado, L. Echegoyen, P. Seiler and F. Diederich, Chem. Commun. 2000, 19, 1859.

[43] V. S. P. K. Neti, M. R. Ceron, A. Duarte-Ruiz, M. M. Olmstead, A. L. Balch and L. Echegoyen, Chem. Commun. 2014, 50, 10584.

[44] R. Tao, T. Umeyama, T. Higashino, T. Koganezawa and H. Imahori, Chem. Commun. 2015, 51, 8233 .

[45] B. Zhang, J. Subbiah, Y.-Y. Lai, J. M. White, D. J. Jones and W. W. H. Wong, Chem. Commun. 2015, 51, 9837.

[46] B. Zhang, J. M. White, D. J. Jones and W. W. H. Wong, Org. Biomol. Chem. 2015, 13, 10505.

[47] X. Meng, G. Zhao, Q. Xu, Z. a. Tan, Z. Zhang, L. Jiang, C. Shu, C. Wang and Y. Li, Adv. Funct. Mater. 2014, 24, 158.

[48] F. Steiner, S. Foster, A. Losquin, J. Labram, T. D. Anthopoulos, J. M. Frost and J. Nelson, Mater. Horiz. 2015, 2, 113.

[49] C. Koidis, S. Logothetidis, S. Kassavetis, C. Kapnopoulos, P. G. Karagiannidis, D. Georgiou and A. Laskarakis, Sol. Energy Mater. Sol. Cells 2013, 112, 36.

[50] S. T. Turner, P. Pingel, R. Steyrleuthner, E. J. W. Crossland, S. Ludwigs and D. Neher, Adv. Funct. Mater. 2011, 21, 4640.

[51] H. G. T. G.E. Irene, Handbook of Ellipsometry, William Andrew Publishing, Norwich, NY 2005.

[52] D. Georgiou, A. Laskarakis, M. Morana, P. G. Karagiannidis and S. Logothetidis, Sol. Energy Mater. Sol. Cells 2014, 125, 190.

[53] S. Logothetidis, Thin Films Handbook: Processing, Characterization and Properties, Academic Press 2001. 
[54] W.-P. Wu, L.-L. Deng, X. Li and Y. Zhao, Sci. Bull. 2016, 61, 139.

[55] E. Chibowski and R. Perea-Carpio, Adv. Colloid. Interface Sci. 2002, 98, 245.

[56] C. M. Cardona, W. Li, A. E. Kaifer, D. Stockdale and G. C. Bazan, Adv. Mater. 2011, $23,2367$. 